\title{
Cost models of additive manufacturing: A literature review
}

\author{
G. Costabile ${ }^{a}$, M. Fera ${ }^{b^{*}}$, F. Fruggiero ${ }^{c}$, A. Lambiase ${ }^{a}$ and D. Pham ${ }^{d}$
}

${ }^{a}$ University of Salerno - Department of Industrial Engineering - Via Giovanni Paolo II, Fisciano (SA) - Italy

${ }^{b}$ Second University of Naples - Department of Industrial and Information Engineering - Via Roma 29, Aversa (CE) - Italy

${ }^{c}$ University of Basilicata - School of Engineering - Via Nazario Sauro, 85, 85100 (PZ) - Italy

${ }^{d}$ Department of Mechanical Engineering - University of Birmingham - Edgbaston, Birmingham B15 2TT, UK

\section{H R O N I C L E}

Article history:

Received July 42016

Received in Revised Format

August 162016

Accepted September 32016

Available online

September 52016

Keywords:

Additive manufacturing

Additive manufacturing cost

model \begin{abstract}
A B S T R A C T
From the past decades, increasing attention has been paid to the quality level of technological and mechanical properties achieved by the Additive Manufacturing (AM); these two elements have achieved a good performance, and it is possible to compare this with the results achieved by traditional technology. Therefore, the AM maturity is high enough to let industries adopt this technology in a more general production framework as the mechanical manufacturing industrial one is. Since the technological and mechanical properties are also beneficial for the materials produced with AM, the primary objective of this paper is to focus more on managerial facets, such as the cost control of a production environment, where these new technologies are present. This paper aims to analyse the existing literature about the cost models developed specifically for AM from an operations management point of view and discusses the strengths and weaknesses of all models.
\end{abstract}

\section{Introduction}

Nowadays, globalization, high competition and a shift towards buyers' market are some of the main challenges faced by the manufacturing industry. In this modern manufacturing environment, effective and flexible manufacturing processes are the foundation of successful in everyday businesses. Buyers look for innovative, customized and high-quality products but they do not want to pay high prices as the same time. Additionally, the economic lifespan of these products decreases with the necessity of having shorter time-to-market and shorter development cycles. Furthermore, the individualization of customer demands increases with an increase of different variants. One possibility to encounter these developments may be delivered by the production technology of Additive Manufacturing (AM) (Lindemann et al., 2015). According to ASTM (2012). "AM can be defined as a collection of technologies able to join materials to make objects from 3D model data, usually layer upon layer, as opposed to subtractive manufacturing methodologies". The technology was created in 1986 when Charles Hull received a patent

* Corresponding author.

E-mail: Marcello.FERA@unina2.it (M. Fera)

(C) 2017 Growing Science Ltd. All rights reserved. doi: $10.5267 /$ j.ijiec.2016.9.001 
(Hull, 1986) for the production of 3D objects using stereolitography. Rapid prototyping (RP) was the natural application of this new production technique for many years. The improvement of mechanical characteristics and quality, the advent of new technology (fused deposition modelling and laser sintering) and the new materials (from polymers to metals) enable the RP to realize objects with the same characteristics of finished products realized by traditional manufacturing systems. In the AM technology, Rapid Tooling (RT) and Rapid Manufacturing (RM) are used differently to suite the customer's needs on the characteristics of the product.

Nowadays, there are different technologies for various types of materials, quality and energy sources; however, all of these have some actions in common:

- Create a design CAD model;

- Convert the CAD model into STL format;

- Slice the STL file into thin cross-sectional layers;

- Construct the model layer by layer;

- Clean and finish the model (i.e. support removal and surface treatments).

Additive technology has various advantages and disadvantages. Some of these have been identified by Lindemann et al. (2012) and are listed below:

\section{Advantages:}

- More flexible development;

- Freedom of design and construction;

- Less assembly;

- No production tool necessary;

- Less spare parts in stock;

- Less complexity in business because less parts to manage;

- Less time-to-market for products;

- Faster deployment of changes.

\section{Disadvantages:}

- High machine and material costs;

- Quality of parts is in need of improvement;

- Rework is often necessary (support structures);

- Building time depends on the height of the part in the building chamber.

In addition to advantages and disadvantages, AM has a deep impact on manufacturing systems requiring different approaches in design and operations management. It is possible to realize high shape complexity without increasing the production costs (contrary to traditional technology). Freedom of design impacts the weight of the object that can be made lighter. Reduction of weight has impacts on lifecycle cost, material cost and energy consumption in the production phase.

Production lead time and supply chain are the other important aspects upset by AM.

Even if each aspect is crucial in the manufacturing systems, the impact on the costs is the most important aspect that a decision maker has to analyse before choosing a new technology. To understand AM advantages, it is necessary to analyse its impact on production management area. Nowadays, the high costs of the machines and materials make technology more expensive than traditional ones, and its use seems to be good only for a low volume of production (Ruffo et al., 2006). Furthermore, some researchers have based their studies on cost models of additive technology based on different costs structures of AM. 
Every cost models of AM focuses on a specific technology aspect like large scale production, time and energy estimate, relevant activities involved and sensitivity analysis on the parameters of the costing model.

This study aims to explore the most relevant cost models defined about the AM. We will examine similarities and differences in all of them, showing their strengths and weaknesses.

\section{Literature review method}

Before starting with the literature review, it is important to develop the method being applied in the literature review. The number of papers on AM to examine is very big; therefore, it is possible to approach that problem by defining a method that can analyse and select the papers automatically.

The procedure is divided into the following several steps:

- Definition of the keywords;

- Collection of papers from the main international scientific papers' database;

- Analysis of the papers' characteristics among the first 100 papers sorted by relevance;

- Selection of the most interesting theme defined by the keyword;

- Eventual knowledge lack of literatures.

The following keywords were investigated: (i) additive manufacturing overview and additive manufacturing technology, (ii) additive manufacturing cost models and additive manufacturing business model, (iii) additive manufacturing mechanical properties and additive manufacturing material, (iv) additive manufacturing supply chain, (v) additive manufacturing sustainability and (vi) additive manufacturing lifecycle cost.

\subsection{Review on general aspects of $A M$}

Fig. 1 and Table 1 show the total and the trend of the papers accepted from 1997 to date and the trend of curves shows a growth for each keyword selected. Until today, researchers have focused on general aspects and technological characteristics of AM (see

Fig. 2). Lifecycle cost, sustainability, supply chain and production costs have been less focused on.

\section{Table 1}

Papers from 1997 to date, per keyword (data source: ScienceDirect)

\begin{tabular}{ll}
\hline Keywords & Number of papers \\
\hline AM overview, AM technology & 34165 \\
AM cost model, AM business model & 3001 \\
AM mech. properties, AM material & 18825 \\
AM supply chain & 7285 \\
AM sustainability & 2466 \\
\hline AM lifecycle cost & 1022 \\
\hline Total & 66764 \\
\hline
\end{tabular}

General aspects of AM (Bikas et al., 2015; Bogers et al., 2016; Brans, 2013; Cardaropoli et al., 2012a; Ferro et al., 2016; Gao et al., 2015; Go \& Hart, 2016; Hedrick et al., 2015; Kianian et al., 2016; Lindemann et al., 2015; Mellor et al., 2014; Muita et al., 2015; Nickels, 2016; Rayna \& Striukova, 2016; Scholz et al., 2016; Winkless, 2015; Wits et al., 2016; Wong \& Hernandez, 2012); industry (Brettel et al., 2016; Gaub, 2015; Fera \& Macchiaroli, 2010; Stock \& Seliger, 2016); implications of its use (Bogers et al., 2016; Huang et al.; Newman et al., 2015; Rayna \& Striukova, 2016); example of its application (Caiazzo et al., 2013; Cardaropoli et al., 2012b; Gupta et al., 2016; Huang et al.; Uhlmann et al., 2015; Wits et al., 2016); flexibility (Brettel et al., 2016; Cox et al., 2016) and technology selection (Newman et al., 2015) allow us to contextualize AM in an actual production system. There are many papers on mechanical characteristics, microstructures and properties (Brugo et al., 2016; Hinojos et al., 2016; 
Huynh et al.; List et al., 2014; Ma et al., 2016; Naghieh et al., 2016; Ordás et al., 2015; Palanivel et al., 2016; Park \& Rosen; Park et al., 2014; Quan et al., 2016; Shamsaei et al., 2015; Thompson et al., 2015; Wang et al., 2015, 2016; Yang et al., 2015) and on structural imperfections (Cardaropoli et al., 2012c; Cheng \& Chou, 2015; Dietrich \& Cudney, 2011; Nouri et al., 2016; Witherell et al., 2016) but, in our research, we found few papers on the themes of sustainability (Bechmann, 2014; Belkadi et al., 2015; Burkhart \& Aurich, 2015; Chen et al., 2015; Ford \& Despeisse; Gebler et al., 2014; Giret et al., 2015; Gupta et al., 2016; Huang et al.; Le Bourhis et al., 2014; Nyamekye et al., 2015; Sreenivasan et al., 2010); lifecycle cost (Cozmei \& Caloian, 2012; Gebler et al., 2014; Fera \& Machiaroli, 2009; Nyamekye et al., 2015; Petek Gursel et al., 2014; Watson \& Taminger; Würtz et al., 2015); supply chain (Barz et al., 2016; Bogers et al., 2016; Emelogu et al.; Gress \& Kalafsky, 2015; Jia et al., 2016; Khajavi et al., 2014; Mellor et al., 2014; Nyamekye et al., 2015; Pinkerton, 2016; Scott \& Harrison, 2015; Silva \& Rezende, 2013; Thomas, 2015) and cost models (Achillas et al., 2015; Alexander et al., 1998; Baumers et al., 2016; Klahn et al., 2015; Lim et al., 2012; Mellor et al., 2014; Piili et al., 2015; Sahebrao Ingole et al., 2009; Schröder et al., 2015; Stucker, 2012; Weller et al., 2015). All these aspects are topics of interest for our research group and, among these aspects, after solving technological problems (materials, tolerances and mechanical characteristics), production cost is the most important matter to be analysed. For this reason, we decide to extend the study to older cost models before AM existed. Older models, in fact, were created to calculate the cost of RP. In the following paragraph, we will analyse the most important work on the technology focusing on the approach and point of view of each author and giving a critical observation on their works.

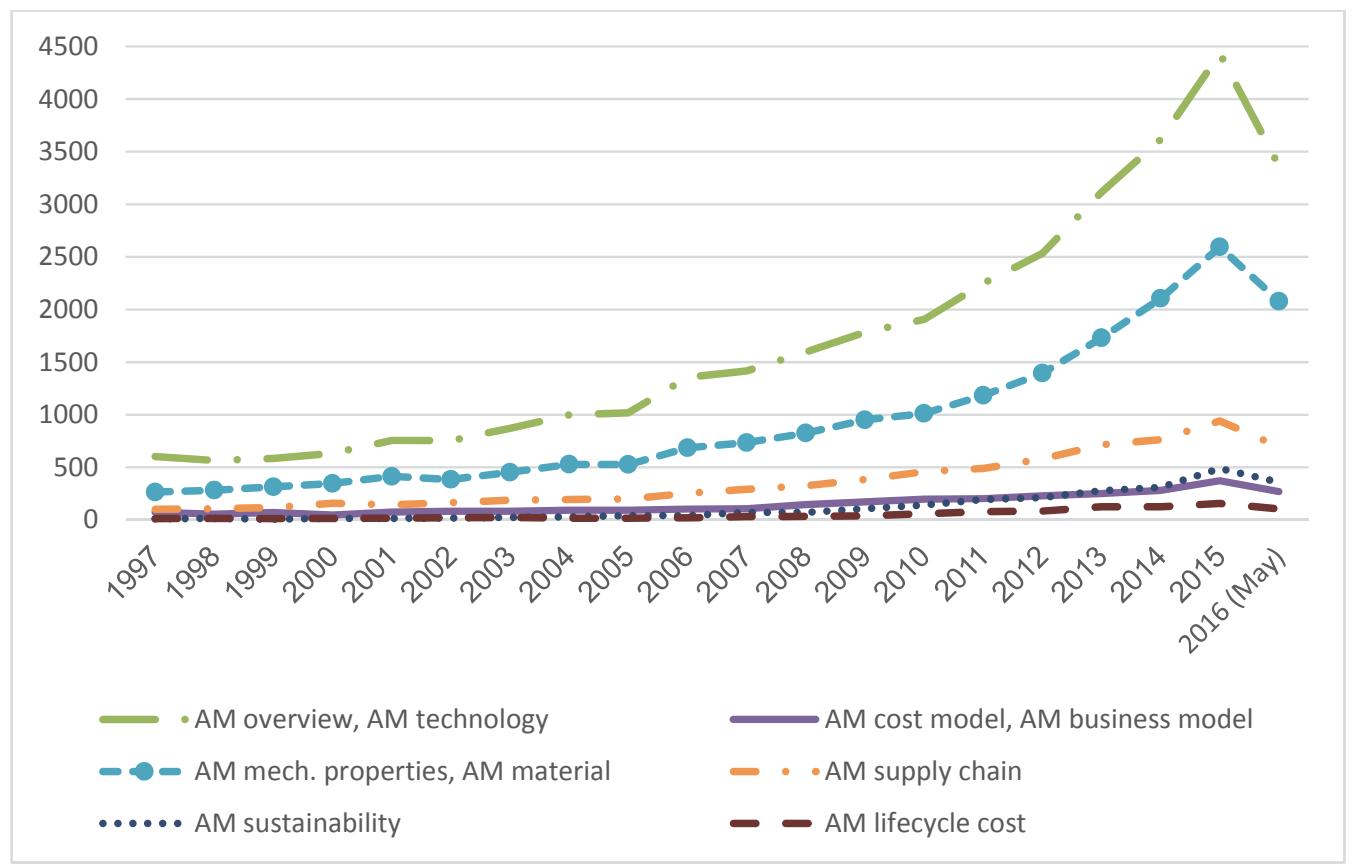

Fig. 1. Number of papers per year and per keyword

Hopkinson and Dicknes (2003) (HD) are among the first who realized an analysis of the AM costs. Initially, the technology was mainly used for RP and RT. However, the authors provided for a development of technology that would allow the realization of finished products in large scale. They reported a cost analysis to compare the traditional manufacturing method of injection moulding (IM) with layer manufacturing processes (stereolithography, fused deposition modelling and laser sintering) in terms of the unit cost for parts made in various quantities (see the example in Fig. 3). The results showed that, for some geometries, up to relatively high production volumes (in an order of a thousand pieces), it is more advantageous to use the layer manufacturing methods. According to HD, AM offers clear advantages compared to traditional technology, such as the lack of moulds and the facility of creating very complex geometries, where in some cases are not achievable just with injection moulding. 
The absence of tooling also reduces a significant amount in the product development process at an early stage.

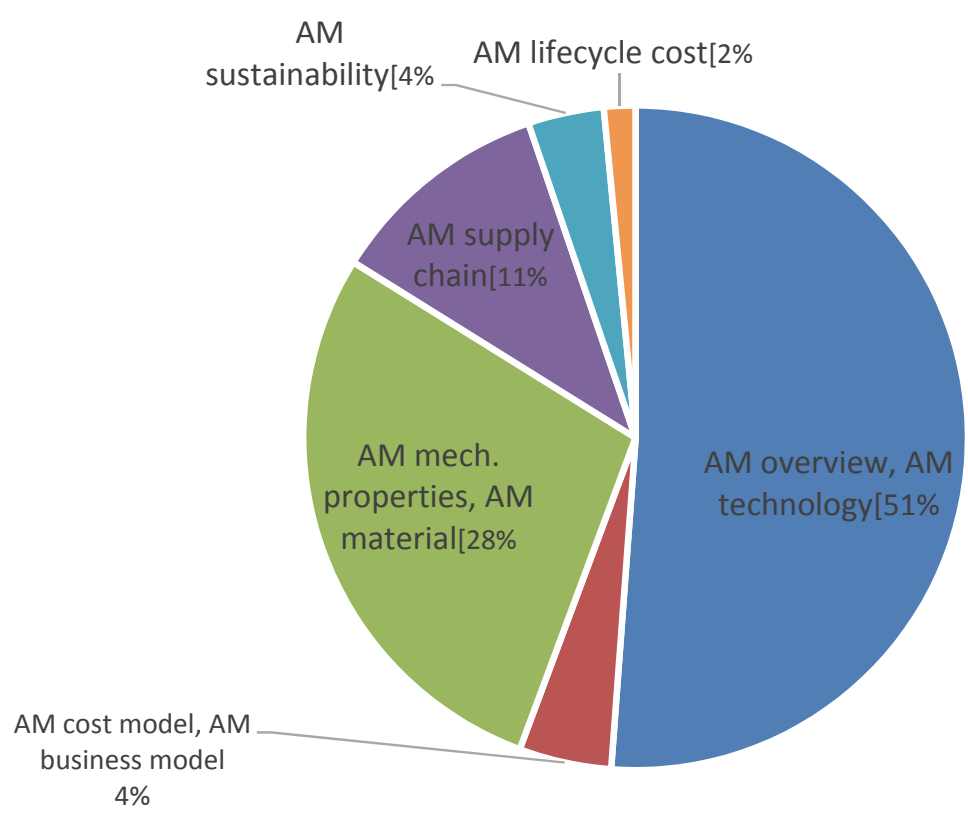

Fig. 2. Mix of papers on Additive Manufacturing

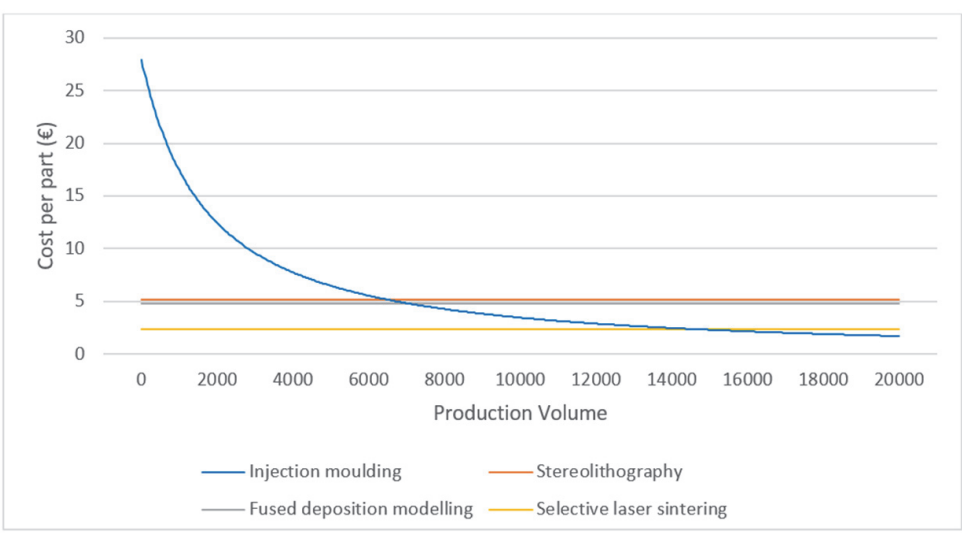

Fig. 3. Cost comparison for the lever by different processes

The costs of the parts were broken down into machine costs, labour costs and material costs.

Total cost per part $=$ Machine cost per part + Labour cost per part + Material cost per part

These costs were calculated assuming that a machine produces one part constantly for one year. The material used for production is polyamide.

\section{Observations}

The proposed model provides an approximation of the costs in different additive technologies. The work was realized when the technology had not matured; later, different aspects of Hopkinson and Dickens' research were further developed and improved by other researchers. The list of the observations is given below: 
- The model does not consider the recycling of non-sintered powder (Ruffo et al., 2006);

- Production volume is not originated by market demand, but it is obtained by multiplying production rate $[\mathrm{parts} / \mathrm{h}$ ] with machine uptime. This assumption is misleading because the cost model should also calculate production costs for different productive contexts where the market demand is a variable and the machine does not work under the same conditions.

- The hypothesis of production of the same component for a whole year cancels one of the main advantages of the additive technologies: the simultaneous production of different parts (Baumers, 2012). Furthermore, the break-even point of the production costs for the lever of Laser Sintering (LS) compared to the Injection Moulding (IM) is achieved for a volume of about 14000 pieces. This suggests an economic advantage of using the LS for lower volumes; however, with the production rate stated at 17.66 parts per hour, this quantity can be achieved in about 37 days. That seems to be in conflict with the assumption of the same piece production for a full year.

- HD calculate unit cost of production in saturation conditions of the machine chamber. For this reason, the technology does not show economies of scale. Nevertheless, it is necessary to analyse production costs even in cases where the chamber is not full. The curve of production costs should have a deflection (Ruffo et al., 2006).

- Power consumption is considered but not included because of its low impact in total costs.

- The model does not consider further processing (i.e. surface finishing, often necessary for addictive technologies). To compare SLS with IM it is necessary realize objects with the same characteristics.

- HD set the machine uptime to $90 \%$ of the total time (365 days $\times 24$ hours), like IM, for high-volume manufacturing systems. In this way, they set the operation time as 7884 hours (328.5 days/year). This assumption leads to an overestimation of the machine working time. The approach of working over 46 weeks per year, twenty-four hours per day, seems to be extremely high.

- The costs for injection moulding were obtained by quotes for unit cost of tooling plus unit costs for each moulding produced. It is unclear how the authors calculate the unit cost per part. The authors do not include typical industrial cost factors like energy cost, machine depreciation and labour costs.

- The authors neglected the impact of RM on lead time and time-to-market. Usually, for IM, the timeto-market is high; in fact, many weeks are necessary to build a moulding tool for a new product, while for the RM, this time is drastically lower, due to the possibility to start (if the raw material is available) directly with the production of the part and not needing the tools for moulding; even so, it is important to note that the cycle time for RM is, normally, longer than the IM one. These aspects have not been considered in IM-RM comparison of this paper.

Hopkinson and Dickens were the first researchers who analysed the RP costs. The hypothesis of a large scale production shifts the focus away from prototyping to manufacturing usage of additive technologies. Our observations show a rather rough economic model. Probably it is due to the incomplete understanding of technology potentiality and because the technology has offered performance very lowers than today.

Some of the observations made on the HD model were analysed and resolved by Ruffo et al. (2006). The model considers a high impact of the overhead costs of the technology analysed. Ruffo et al. (2006) analysed the production of the same object (lever) used by Hopkinson and Dickens, that is obtained by laser sintering. The HD model assumed an allocation of indirect costs on the basis of annual production volume: this caused a constant unit cost when measured with the quantity produced. According to Ruffo et al. (2006), this assumption is incorrect. Injection moulding, in fact, amortizes the cost of the mould in the initial phase of production, showing a deflection of the curve cost (like in Fig. 3). In the same way LS amortizes the cost of the machine in the initial production phase. Ruffo et al. (2006) asserted that cost curve for both technologies must have the same trend. The model offers a breakdown cost structure in various activities (activity based costing). This approach comprises a definition of the activities involved, the calculation of the costs of each activity and in the summing of each cost. Activity costs are then split into direct and indirect costs and are attributed to a single part with a full costing system. The only direct cost is relative to the material used. The costs of labour, machine, production overhead and 
administration overhead are indirectly allocated. Labour and machine maintenance are considered to be indirect as they are paid annually with contracts. Total cost of a single build is the sum of direct and indirect costs. The direct costs depend on the amount of material used and indirect costs depend on the time of construction:

$$
\text { Cost of a build }=\text { Direct costs }+ \text { Indirect costs }
$$

where

Direct costs: material used;

Indirect costs: labour, machine and overheads.

The main differences compared to the previous model are listed below:

- Labour was considered by HD as a direct cost adding its cost directly to the part produced. New model adds the machine operator salary indirectly to the product. Its allocation is proportional to the working time of the machine.

- Material recycle is not considered in the HD model.

- Machine utilization set in HD was $90 \%$ versus the more realistic $57 \%$ of the new model.

- Recycle of material is possible but with limitations due to the thermal treatment of the powder.

This approach, like HD, provides the definition of cost curve for different production volumes. The positioning of the object in the machine chamber is like a 3D matrix in which every element represents an object to build. Starting by the first object we can add the next one until the line is full. Then, to add more objects, we have to start a new line horizontally (on the same layer). When all lines are full, to add more objects, we have to start a new layer (on the top of the previous full layer). When all the available layers are full, if we want to produce more parts, we have to start a new bed (new chamber) repeating the previous phases. Unlike the Hopkinson and Dickens study, which shows a constant cost for the LS parts, the cost curve (Fig. 4) has a deflection for low production volumes and a change in the costs curve tendency whenever one of three following situation arises:

1. It is necessary to use a new row (line) in the $\mathrm{x}$ direction for the addition of a part.

2. It is necessary to add a new vertical layer for the addition of a part.

3. It is necessary to start a new bed for the addition of a part.

This trend is justified by extra time and materials necessary to produce more parts. The saw tooth trend is caused by the impact of a fixed time element for every build (warm-up and cool-down) and every layer (powder deposition time). Increasing the number of parts in every layer and every build, the effect of fixed time consumption (and consequently of costs) will be lower. Instead, the increase of the layer number (i.e. adding only one object in a new layer) produces a negative effect on the costs. We have the same negative situation when we start a new bed containing only one part.

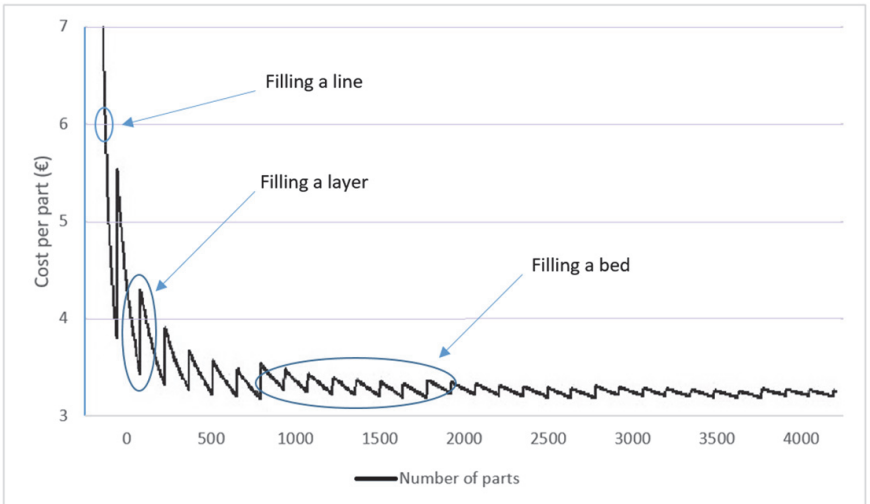

Fig. 4. Production curve for the lever (Laser Sintering) 
The cost of the single piece, according to the new model, is significantly higher than the cost calculated by Hopkinson and Dickens (2006). The comparison evidences a cost underestimation of the old model. For high production volumes, the curve tends to stabilize because of the indirect cost splitting on a higher number of parts.

\section{Observations}

The possibility to recycle the powder and a more accurate analysis of the overhead costs make the Ruffo et al. (2006) model more accurate than HD model. Moreover, the trend of the saw tooth curve of the unit cost means that the model is very sensitive to the number of parts produced focusing on the build saturation issue. The observations are listed below:

- Energy consumption is considered for the first time by Ruffo et al. (2006), even if its cost has been inserted between overhead costs. This approach is unusual by having the possibility to refer the energy consumption to the single part produced so to its cost.

- Moreover, in this model, no post-processing was taken in account (like the previous model).

- Lead time and time-to-market have not been considered by comparing RM and IM (like the previous model);

- Since Ruffo et al. (2006) consider the same IM unit cost of HD, it is worth noting that this issue was not solved by them;

- Ruffo et al. (2006) set the machine utilization to $57 \%$ of the total time (by contact with industrial partners). In this way, they defined working time in 100 hours/week, for 50 weeks per year. Even if this approach seems more reliable than the previous HD assumption, they do not consider possible failure and maintenance time. HD uses the 'uptime' terminology, while Ruffo et al. (2006) use 'utilization'. In each case, the operating time of the machine is obtained by multiplying the total time (365 days $\times 24$ hours) and the machine utilization (or uptime).

The studies by Baumers (2012) and Baumers et al. (2012) are the first examined ones, in detail, the economic and energetic aspects and also the time necessary to realize the AM construction. The highlights of his work are listed below:

- An activity based cost (ABC) estimator of the type devised by Ruffo et al. (2006) is employed, but energy costs are grouped as direct;

- An estimate of total build time;

- An accurate analysis of energy consumption.

According to Baumers, high indirect costs of AM (time dependent allocated) and the presence of fixed element of time consumption (for each layer and for each build) make the analysis of the build unused capacity problem very important. In this way, it is possible to reduce the effect of indirect costs. Hopkinson and Dickens assumed no excess of capacity because the chamber of the machine is always full. However, Ruffo et al. (2006) also based their estimates on average unit cost on much smaller production quantities and the assumption is that any excess capacity remains unused. From the perspective of economic theory, average cost functions are seen as cost/quantity combinations that are technically efficient. This means that the minimum cost is obtained from the input used. In this contest, Ruffo and Hague (2007) note that "in reality manufacturers set every build with the highest packing ratio possible", which means there is an incentive to completely fill build volumes with products. Another important observation of Baumers et al. (2012) is that break-even costing models may not be able to capture the capabilities of geometrically less restrictive manufacturing processes to create a complex product. Furthermore, in direct competition with conventional mass production, AM faces the disadvantage of not being able to offer the scale economies available to conventional manufacturing processes. For their research, Baumers et al. (2012) employed an activity-based cost estimator of the type devised by Ruffo et al. (2006). The cost estimate for the build is constructed by combining data on the total indirect and direct costs incurred. Indirect costs, expressed as a cost rate measured per machine 
hour, contains costs arising from administrative and production overheads, production labour and machine costs (including depreciation). Unlike Ruffo et al. (2006), energy cost is grouped as a direct cost.

The total cost for each build can be expressed as follows

$$
C_{\text {build }}=\left(\dot{C}_{\text {Indirect }} \times T_{\text {Build }}\right)+\left(w \times P_{\text {Raw material }}\right)+\left(E_{\text {Build }} \times P_{\text {Energy }}\right)
$$

where

$\dot{C}_{\text {Indirect }}: \quad$ indirect cost per machine hour;

$T_{\text {Build }}$ : $\quad$ total build time;

$w: \quad$ total weight of the part in the build (including support structure);

$P_{\text {Raw material }}$ : price per $\mathrm{kg}$ of raw material;

$E_{\text {Build }}$ : total energy consumption per build;

$P_{\text {Energy }}$ mean price of electricity.

The time and energy estimator and the grouping of energy in direct costs make the cost model more accurate than previous ones. Baumers et al. (2012), however, did not consider other activities that are indirectly connected to the phase of building but are still relevant from the economic point of view (postprocessing and material removal). In many cases, it is necessary as a further phase, for example, to enhance mechanical property or to improve surface quality. As we will see later in this study, these activities will be analysed by other researchers. The estimate of the building time is obtained by combining fixed time consumption per build (warm-up and cool-down), layer dependent time consumption (time necessary to add powder) and laser deposition time for the sintering of the powder:

where

$$
T_{\text {Build }}=T_{\text {Job }}+\left(T_{\text {Layer }} \times n\right)+\sum_{z=1}^{z} \sum_{y=1}^{y} \sum_{x=1}^{x} T_{\text {Vovel } x y x}
$$

$T_{J o b}: \quad$ fixed time consumption per build;

$n$ : $\quad$ number of layer;

$T_{\text {Layer }}:$ fixed time consumption per layer;

$T_{\text {Voxel xyz }}: \quad$ time needed to process each voxel;

In the analysis of energy consumption, Baumers et al. (2012) divided total energy between consumption for each job, single layer energy consumption, geometry dependent energy consumption and a constant base line level of energy consumption throughout the build:

$$
E_{\text {Build }}=E_{\text {Job }}+\left(\dot{E}_{\text {Time }} \times T_{\text {Build }}\right)+\left(E_{\text {Layer }} \times l\right)+\sum_{z=1}^{z} \sum_{y=1}^{y} \sum_{x=1}^{x} E_{\text {Vovel } x y x}
$$

where

$E_{J o b}: \quad$ fixed energy consumption per build;

$\dot{E}_{\text {Time }}: \quad$ fixed energy consumption rate;

$E_{\text {Layer }}$ : fixed energy consumption per layer;

$l: \quad$ number of layer;

$E_{\text {Voxel xyz: }}: \quad$ energy needed to process each voxel;

\section{Observations}

The observation on previous works (HD and Ruffo et al.) and the quality of the build time and energy estimator are further important steps. These observations concur to better understand AM performance in terms of costs and potentiality. 
Even if Baumers et al. (2012) group energy costs as direct (more accurate costing), their cost model is the same as the type devised by Ruffo et al. (2006); therefore, the observations derived from the previous cost model (see Ruffo et al.) are still valid. Lindemann et al. (2012) asserted that Hopkinson and Dickens and Ruffo et al. (2006) chose a similar approach for the calculation of costs in their models and each of them set a specific emphasis on a certain topic. In sum, we could say that every existing costing model has advantages and disadvantages; however, no single model satisfies all criteria. Thus, there is a need to combine the strengths of existing models without including their weaknesses and develop a new costing model that is suitable for the calculation of today's AM. Before developing a cost model, all relevant cost processes of the AM production process, have been investigated and modelled with Eventdriven Process Chains. As a calculation method, a "Time Driven Activity Based Costing" approach has been adopted. "Time Driven" means that the allocation depends on the duration of the activities. For the estimation of relevant cost processes, Lindemann et al. (2012) define four main processes:

- Building job preparation;

- Building job production;

- Sample parts and support manually removing;

- Post processing to enhance material properties.

The main processes were selected to be able to represent different cost centres. This facilitates the calculation and makes it easier to adopt the model to different production environments.

The framework of machine cost per build defined by Lindemann et al. (2012) is structurally similar to the previous framework defined by Ruffo et al. (2006). The differences are due to:

- Electrical energy cost and gas cost per hour grouped as direct costs;

- Fixed costs per every build (labour costs and gas costs).

The material cost is defined in the same way defined by Ruffo.

For completeness we show the formulation of the costs structure stated by the authors. The cost of a single build is obtained by summing the activities costs $\left(A_{i}\right)$ involved:

$$
\text { Cost of a build }=\sum_{i} A_{i}
$$

\section{Observations}

Lindemann et al. (2012) are among the first researchers who included the post-processing activity in the costing model. This activity includes, for example, quality control, surface treatment and support removal. Some of the items included in the post processing activity are unavoidable in all additive processes. For this reason, the idea of considering the cost of the post processing phases helps to better understand the economic aspects related to the technology.

According to Rickenbacher et al. (2013), AM processes are interesting candidates for the replacement of conventional production processes like cutting or casting. The integration of AM processes into a production environment requires a cost-model that allows the estimation of the real costs of a single part, although it might be produced in the same build job together with other parts of different geometries. The highlights of the cost model proposed by Rickenbacher et al. (2013) are listed below:

- Cost calculation of single part in a build (assuming a contemporary production of different parts),

- Deep analysis of the steps involved in the process,

- Cost model including all pre- and post- processing steps linked to AM processes,

- Algorithm to calculate the time fraction for each part in the build job,

- Build time estimator derived by a linear regression on 24 different build jobs. 
The cost model is based on the generic cost model of Alexander et al. (1998). The cost of the single part $\left(P_{i}\right)$ is obtained summing the costs of the seven process steps which is defined below:

$$
\begin{gathered}
C_{\text {tot }}\left(P_{i}\right)=C_{\text {Prep }}\left(P_{i}\right)+C_{\text {Buildjob }}\left(P_{i}\right)+C_{\text {Setup }}\left(P_{i}\right)+C_{\text {Build }}\left(P_{i}\right)+C_{\text {Removal }}\left(P_{i}\right)+C_{\text {Substrate }}\left(P_{i}\right) \\
+C_{\text {Postp }}\left(P_{i}\right)
\end{gathered}
$$

where

$C_{\text {tot }}\left(P_{i}\right): \quad$ total manufacturing costs,

$P_{i}$ : $\quad$ part with $i$ th geometry,

$C_{\text {Prep }}\left(P_{i}\right)$ : cost for preparing geometry data (orientation, support structures, etc.),

$C_{\text {Buildjob }}\left(P_{i}\right)$ : cost for build job assembly,

$C_{\text {Setup }}\left(P_{i}\right)$ : machine set up costs,

$C_{\text {Build }}\left(P_{i}\right)$ : cost for building up the part,

$C_{\text {Removal }}\left(P_{i}\right)$ : cost for removing the part from the SLM machine,

$C_{\text {Substrate }}\left(P_{i}\right): \quad$ cost to separate parts from substrate plate,

$C_{\text {Postp }}\left(P_{i}\right)$ : cost for post-processing.

Rickenbacher et al. (2013) also developed an algorithm to calculate the time fraction for each part in the build job. The algorithm allows calculating the layer-dependent fraction of total build time per part. In Fig. 5, we can see that in dark grey three parts are affected, two in the grey slice and so on. The allocation criterion of time could be proportional to the corresponding cross-section of the part or proportional to the amount of layers of the slices defined.

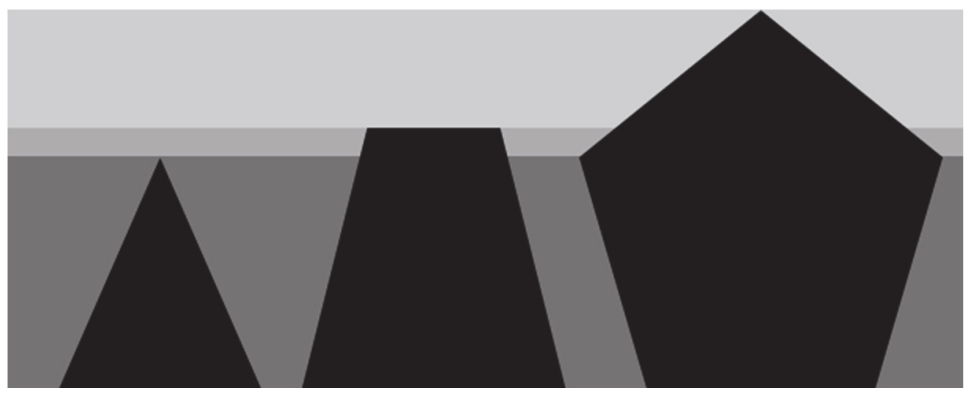

Fig. 5. Simultaneous build-up of multiple parts with different heights

The algorithm suggests optimizing the use of building space by simultaneously building up as much geometries with similar part height as possible.

To estimate build time, Rickenbacher et al. (2013) used a linear regression model derived from 24 different build jobs. He defines the following equation that allows to calculate the regression coefficients:

$$
\sum_{i} T_{\text {Build }}\left(P_{i}\right)=a_{0}+a_{1} * N_{L}+a_{2} \times V_{\text {tot }}+a_{3} \times S_{\text {Supp tot }}+a_{4} \times \sum_{i} N_{i}+a_{5} * S_{\text {tot }}
$$

where

$T_{\text {Build }}$ : building time;

$P_{i}$ : $\quad$ part with $i$ th geometry;

$a_{0}, \ldots, a_{5}: \quad$ regression coefficients;

$N_{L}: \quad$ number of layers;

$V_{\text {tot }}: \quad$ total volume of building job;

$S_{\text {Supp }}$ tot $:$ total surface area of the support structures,

$N_{i}$ : $\quad$ quantity of parts with $i$ th geometry;

$S_{\text {tot }}: \quad$ total surface area of the build job. 
These regression coefficients $\left(a_{0}, \ldots, a_{5}\right)$ will be used to calculate the total build time of each part using the following equation:

$$
T_{\text {Build }}\left(P_{i}\right)=\frac{a_{0}}{\sum_{i} N_{i}}+T_{L} P_{i}+a_{2} * V\left(P_{i}\right)+a_{3} \times S_{\text {Supp }}\left(P_{i}\right)+a_{4}+a_{5} \times S\left(P_{i}\right)
$$

where

$T_{\text {Build }}$ : building time;

$P_{i}$ : $\quad$ part with $i$ th geometry;

$a_{0}, \ldots, a_{5}: \quad$ regression coefficients;

$T_{L}$ : layer-dependent fraction;

$V$ : volume of the part;

$S_{\text {Supp }}: \quad$ surface area of the support structures,

$N_{i}: \quad$ quantity of parts with $i$ th geometry;

$S: \quad$ surface area of the part.

\section{Observations}

- Even if the cost model includes a detailed analysis of the pre- and post-processing related to the AM process, a possible material removal step has not been included.

- Like all previous cost models, Rickenbacher et al. (2013) assert that it is possible to have a lower unit cost of the parts by building more parts in the same build job.

- Machine's cost per hour $[€ / \mathrm{h}]$ included in idle phases of the machine (Setup and Removal steps).

- Reliable computation of the effect of material change and additional work of using inert gas have been included in the machine set up costs by using the factors $F_{\text {Inertgas }}$ and $F_{\text {Mat.Change }}$.

- Proposed algorithm to allocate the time fraction of the total build time to each part realized is simple and effective.

- The authors consider labour cost as an hourly rate multiplied for the duration of each step where operator is necessary. The operator hourly cost for each step of production $(90 € / \mathrm{h})$ is assumed equal for any kind of worker is involved. In our opinion, this should be a strong limitation of the generality of the model proposed because it is normal to have different labour hourly cost for different skills.

- The cost model does not take in account energy consumption and its cost. We disagree with this approach because this item is not negligible in metal AM processes.

- The authors do not explain which cost items is included in the machine's cost per hour.

- In our opinion, it is tough to assign a realistic weight to the way in which the authors predict the building time through a formula of estimation that is calculated with different parameters very different among themselves. The parameters are referred also to surface area of support structure and surface area of building job; these are related to a shape complexity element that is out of the game when the matter is focused on the AM and that is well known as a technology complexity free. Moreover, in the equation used for total build time, calculation does not derive explicit possible warm-up time and cool-down time. Due to the deep impact of these fixed elements of time consumption in some additive technologies, we think that it is correct to analyse these parameters. Moreover, it is very important to note that the authors do not validate their time estimation approach in anyway.

This cost model represents a good step forward in the effectiveness of cost estimation of AM. Even if we have doubts on quality of the time estimator, the deep analysis of pre- and post-processing and the algorithm defined to calculate the time fraction for each part in the build job are important tools for AM technology. The work of Schröder et al. (2015) states the AM business models in the literature review, the development of a business model that evaluates the process costs of AM technologies and a sensitivity analysis on the output of theur Excel tool. In their review, they analyse the main business models developed for the different AM processes. The outcome of their study is the summary of the requirement 
of the new cost model necessary to represent costs completely and realistically. The requirements of the new cost model are listed as follows:

- Integration of recycling and waste of material;

- Integration of support structures of products including a general appraisal for different AM processes;

- Calculation of the printing time;

- Maximum possible number of products that can be printed simultaneously in the workspace;

- Level of complexity of the product;

- Duration of the post-processing;

- Integration of modern quality management methods for the protection and monitoring of product and process quality.

For the development of their business model, Schröder et al. (2015) use an activity based costing. The relevant activities are defined using interviews submitted to a group of experts (small and medium companies having experience on AM technologies) and researchers on AM. The following seven main process steps were identified:

- Design \& planning;

- Material processing;

- Machine preparation;

- Manufacturing;

- Post-processing;

- Administration and sales;

- Quality.

An Excel cost calculation tool has been developed to provide both costs and a sensitivity analysis as output. For completeness, we show the formulation of the costs structure stated by the authors. The cost of a single build is obtained by summing the activities costs $\left(A_{i}\right)$ involved:

$$
\text { Cost of a build }=\sum_{i} A_{i}
$$

The sensitivity analysis is made to identify special economic effects of AM. The main findings are

- The most cost-influencing factors are the investment costs of the machine and its load factor;

- The post-processing of products with high quantities and small bodies has a big potential for process optimization;

- Economies of scale only exist for small products; products with big bodies are nearly independent from the ordered quantity.

\section{Observations}

Schröder et al. (2015) increased the number of the relevant activities included in their cost model. Design and planning were not included in each of the cost models analysed. Probably one of the most interesting is the design activity. AM, in fact, compared with subtractive technologies, requires extra design phases. This phase is not present for the case of building exactly the same part typically obtained by subtractive technologies; however, in most cases, AM is able to realize complex geometries that are not achievable using material removal technique. In all of these cases, costs of redesign have to be considered to have a more accurate cost of the finish product. This cost model gives certainly an accurate analysis of additive technologies. The relevant activities included, not directly related to the building phase, give an overview on additive processes that no models have been able to realize. However, we are unsure of the definition of administrations and sales activities. The cost model for AM should include only industrial costs. 
Administrative and sales should be included in cost accounting with all other overhead costs. Furthermore, these cost items are invariant respect to the technology adopted; therefore, for this reason, if we want use the cost model to compare different technologies, it is not necessary to consider them.

\section{Conclusions}

Regardless of the technology in question (DMLS, EBM, LS, SLA and FDM), we can identify similar process phases that allow the definition of a single cost model valid for each of them. Some of involved factors are labour, machine, material, power source, warm-up time, build rate and energy consumption. By varying these factors, we obtain a different costs impact on the finished product.

Over time, every author adds something to the previous cost model allowing an increase of accuracy.

Older models, by comparing Laser Sintering with Injection Moulding, disprove affordability for large scale production (Hopkinson \& Dicknes, 2003; Ruffo et al., 2006). Scarce understanding of the technology led to the development of crude cost models that do not consider effectively all involved variables (energy consumption and labour). Ruffo et al. (2006) and Hopkinson et al. (2003) used a microeconomic approach (break-even analysis). Both understood the potentiality of AM in chamber saturation condition, but they focused on large scale production (economic approach) instead of efficiency of the process (engineering approach). Subsequently different work, in this direction, was realized by Baumers et al. (Baumers et al., 2011a, 2011b). In their experiments, they investigated the impact of capacity utilization of the machine on time, energy consumption and total costs.

Over time, we have had an increase of the detail level of the business models defined. We pass from the initial crude cost models, through the accurate definition of time and energy consumption realized by Baumers et al. (2012) up to the Schröder et al. (2015) cost model that appears to be very accurate. Another important aspect to be considered is related to materials used in AM. Originally AM, or better Rapid prototyping, only allowed the production of polymeric object and it was compared with injection moulding. For large scale productions, IM shows a low and descending unit cost of the product. The absence of economies of scale in AM and the high costs involved in terms of machine and materials make the technology suitable only for low production volumes.

Related to materials, we have to acknowledge energy consumption. Hopkinson and Dickens assumed energy consumption cost as negligible for its low effect on total cost. At the time, additive processes were suitable only to realize polycarbonate and polypropylene objects. Subsequently, Ruffo et al. (2006) considered energy costs even if they were inserted between overhead costs. Higher energy consumption necessary to realize metallic objects made essential to take into account this cost item. In this context, Baumers et al. (2012) analysed the theme and inserted energy between direct costs. Older cost models do not consider any post processing (HD and Ruffo et al. and Baumers et al.). However, Lindemann et al. (2012), Rickenbacher et al. (2013) and Schröder et al. (2015) consider post-processing activities like surface treatments and quality controls. In some cases, AM can be a substitute of subtractive manufacturing, whereas in other cases, after the building process using AM, some mechanical characteristics of the parts need to be enhanced (i.e. rugosity and tolerances) (Atzeni \& Salmi, 2012). It should be interesting to hypothesize a hybrid production model that includes the post-processing cost of AM, not only in terms of quality controls and support removal but in terms of material removal (Campbell et al., 2012; Manogharan et al., 2015). Existing cost models consider the activities directly connected to building process of AM; however, due to the fact that AM allows the production of end use product, it is important to include in the cost model all the activities involved to the calculation of the full cost of a finish part like, for example, redesign costs (Eleonora Atzeni et al., 2010; Hague et al., 2003) and material removal cost (Manogharan et al., 2016). For this reason, the definition of a new cost model appears necessary. As stated in the initial part of this paper, it aimed to define a critical analysis about the cost models for AM from an operations management point of view. Therefore, further observation regards the approach used by all the authors for defining their cost models. Each of their cost models measures additive systems as separate by their production systems of which they are part. No one takes in account 
aspects like, for example, demand of a product, production mix, lead time and delivery time. For example, the hypothesis of large scale production is made by considering the absolute measure of the production volume of a single machine with no attention to the general market size. Moreover, the hypothesis of cost reduction by increasing the capacity utilization of the chamber could be in contrast with the delivery time; for example, it is not possible to infinitely wait for the saturation achievement if a delivery has to be performed. To consider only additive process were correct if we wanted to measure an individual phase; however, in an integration point of view of AM in a conventional production system, we think that it should be correct to take in account also other aspects like some the previously cited operations, that can be before and after the work phase of AM. From an enterprise point of view, these models appear as scarcely related to the real needs of an industrial company that are generally underestimated from the theoretical approaches. Moreover, it is worth noting that all the observations on the existing cost models, and the synthesis of their strengths and weaknesses, can lay the foundations to define and build a new cost model that will help solve the open issues analysed here.

\section{References}

Achillas, C., Aidonis, D., Iakovou, E., Thymianidis, M., \& Tzetzis, D. (2015). A methodological framework for the inclusion of modern additive manufacturing into the production portfolio of a focused factory. Journal of Manufacturing Systems, 37, Part 1, 328-339. http://doi.org/10.1016/j.jmsy.2014.07.014

Alexander, P., Allen, S., \& Dutta, D. (1998). Part orientation and build cost determination in layered manufacturing. Computer-Aided Design, 30(5), 343-356. http://doi.org/10.1016/S00104485(97)00083-3

ASTM, 2012. (n.d.). ASTM F2792 - 12e1 Standard Terminology for Additive Manufacturing Technologies.

Atzeni, E., \& Salmi, A. (2012). Economics of additive manufacturing for end-usable metal parts. The International Journal of Advanced Manufacturing Technology, 62(9-12), 1147-1155.

Barz, A., Buer, T., \& Haasis, H.-D. (2016). A Study on the Effects of Additive Manufacturing on the Structure of Supply Networks. IFAC-PapersOnLine, 49(2), 72-77. http://doi.org/10.1016/j.ifacol.2016.03.013

Baumers, M. (2012). Economic aspects of additive manufacturing: benefits, costs and energy consumption. Icopyright Martin Baumers. Retrieved from https://dspace.lboro.ac.uk/dspacejspui/handle $/ 2134 / 10768$ ? sequence $=3$

Baumers, M., Dickens, P., Tuck, C., \& Hague, R. (2016). The cost of additive manufacturing: machine productivity, economies of scale and technology-push. Technological Forecasting and Social Change, 102, 193-201.

Baumers, M., Tuck, C., Bourell, D. L., Sreenivasan, R., \& Hague, R. (2011). Sustainability of additive manufacturing: measuring the energy consumption of the laser sintering process. Proceedings of the Institution of Mechanical Engineers, Part B: Journal of Engineering Manufacture, 225(12), 22282239.

Baumers, M., Tuck, C., Wildman, R., Ashcroft, I., \& Hague, R. (2011). Energy inputs to additive manufacturing: does capacity utilization matter? EOS, 1000(270), 30-40.

Baumers, M., Tuck, C., Wildman, R., Ashcroft, I., Rosamond, E., \& Hague, R. (2012). Combined buildtime, energy consumption and cost estimation for direct metal laser sintering. From Proceedings of Twenty Third Annual International Solid Freeform Fabrication Symposium-An Additive Manufacturing Conference, $13 . \quad$ Retrieved from http://sffsymposium.engr.utexas.edu/Manuscripts/2012/2012-71-Baumers.pdf

Bechmann, F. (2014). Changing the future of additive manufacturing. Metal Powder Report, 69(3), 3740. http://doi.org/10.1016/S0026-0657(14)70135-3

Belkadi, F., Bernard, A., \& Laroche, F. (2015). Knowledge Based and PLM Facilities for Sustainability Perspective in Manufacturing: A Global Approach. Procedia CIRP, 29, 203-208. http://doi.org/10.1016/j.procir.2015.01.065 
Bikas, H., Stavropoulos, P., \& Chryssolouris, G. (2015). Additive manufacturing methods and modelling approaches: a critical review. The International Journal of Advanced Manufacturing Technology, 117.

Bogers, M., Hadar, R., \& Bilberg, A. (2016). Additive manufacturing for consumer-centric business models: Implications for supply chains in consumer goods manufacturing. Technological Forecasting and Social Change, 102, 225-239. http://doi.org/10.1016/j.techfore.2015.07.024

Brans, K. (2013). 3D Printing, a Maturing Technology. IFAC Proceedings Volumes, 46(7), 468-472. http://doi.org/10.3182/20130522-3-BR-4036.00112

Brettel, M., Klein, M., \& Friederichsen, N. (2016). The Relevance of Manufacturing Flexibility in the Context of Industrie 4.0. Procedia CIRP, 41, 105-110. http://doi.org/10.1016/j.procir.2015.12.047

Brugo, T., Palazzetti, R., Ciric-Kostic, S., Yan, X. T., Minak, G., \& Zucchelli, A. (2016). Fracture mechanics of laser sintered cracked polyamide for a new method to induce cracks by additive manufacturing. Polymer Testing, 50, 301-308. http://doi.org/10.1016/j.polymertesting.2016.01.024

Burkhart, M., \& Aurich, J. C. (2015). Framework to Predict the Environmental Impact of Additive Manufacturing in the Life Cycle of a Commercial Vehicle. Procedia CIRP, 29, 408-413.

Caiazzo, F., Cardaropoli, F., Alfieri, V., Sergi, V., \& Cuccaro, L. (2013). Experimental analysis of selective laser melting process for Ti-6Al-4V turbine blade manufacturing (Vol. 8677). Presented at the Proceedings of SPIE - The International Society for Optical Engineering. http://doi.org/10.1117/12.2010577

Campbell, I., Bourell, D., \& Gibson, I. (2012). Additive manufacturing: rapid prototyping comes of age. Rapid Prototyping Journal, 18(4), 255-258.

Cardaropoli, F., Alfieri, V., Caiazzo, F., \& Sergi, V. (2012a). Dimensional analysis for the definition of the influence of process parameters in selective laser melting of Ti-6Al-4V alloy. Proceedings of the Institution of Mechanical Engineers, Part B: Journal of Engineering Manufacture, 226(7), 11361142. http://doi.org/10.1177/0954405412441885

Cardaropoli, F., Alfieri, V., Caiazzo, F., \& Sergi, V. (2012b). Manufacturing of porous biomaterials for dental implant applications through Selective Laser Melting. Advanced Materials Research, 535-537, 1222-1229. http://doi.org/10.4028/www.scientific.net/AMR.535-537.1222

Cardaropoli, F., Caiazzo, F., \& Sergi, V. (2012). Evolution of direct selective laser sintering of metals. $\begin{array}{llll}\text { Advanced } & \text { Materials } & \text { Research, 383-390, }\end{array}$ http://doi.org/10.4028/www.scientific.net/AMR.383-390.6252

Chen, D., Heyer, S., Ibbotson, S., Salonitis, K., Steingrímsson, J. G., \& Thiede, S. (2015). Direct digital manufacturing: definition, evolution, and sustainability implications. Journal of Cleaner Production, 107, 615-625. http://doi.org/10.1016/j.jclepro.2015.05.009

Cheng, B., \& Chou, K. (2015). Geometric consideration of support structures in part overhang fabrications by electron beam additive manufacturing. Computer-Aided Design, 69, 102-111. http://doi.org/10.1016/j.cad.2015.06.007

Cox, S. C., Jamshidi, P., Eisenstein, N. M., Webber, M. A., Hassanin, H., Attallah, M. M., ... Grover, L. M. (2016). Adding functionality with additive manufacturing: Fabrication of titanium-based antibiotic eluting implants. Materials Science and Engineering: $C$, 64, 407-415. http://doi.org/10.1016/j.msec.2016.04.006

Cozmei, C., \& Caloian, F. (2012). Additive Manufacturing Flickering at the Beginning of Existence. Procedia Economics and Finance, 3, 457-462. http://doi.org/10.1016/S2212-5671(12)00180-3

Dietrich, D. M., \& Cudney, E. (2011). Impact of integrative design on additive manufacturing quality. International Journal of Rapid Manufacturing, 2(3), 121-131. http://doi.org/10.1504/IJRAPIDM.2011.043454

Eleonora Atzeni, Luca Iuliano, Paolo Minetola, \& Alessandro Salmi. (2010). Redesign and cost estimation of rapid manufactured plastic parts. Rapid Prototyping Journal, 16(5), 308-317. http://doi.org/10.1108/13552541011065704

Emelogu, A., Marufuzzaman, M., Thompson, S. M., Shamsaei, N., \& Bian, L. (n.d.). Additive Manufacturing of Biomedical Implants: A Feasibility Assessment via Supply-Chain Cost Analysis. Additive Manufacturing. http://doi.org/10.1016/j.addma.2016.04.006 
Fera, M., \& Macchiaroli, R. (2010). Use of analytic hierarchy process and fire dynamics simulator to assess the fire protection systems in a tunnel on fire.International Journal of Risk Assessment and Management, 14(6), 504-529. http://doi.org/10.1504/IJRAM.2010.037087

Fera, M., \& Macchiaroli, R. (2009). Proposal of a quali-quantitative assessment model for health and safety in small and medium enterprises. WIT Transactions on the Built Environment, 108. http://doi.org/10.2495/SAFE090121

Ferro, C., Grassi, R., Seclì, C., \& Maggiore, P. (2016). Additive Manufacturing Offers New Opportunities in UAV Research. Procedia CIRP, 41, 1004-1010. http://doi.org/10.1016/j.procir.2015.12.104

Ford, S., \& Despeisse, M. (n.d.). Additive manufacturing and sustainability: an exploratory study of the advantages and challenges. Journal of Cleaner Production. http://doi.org/10.1016/j.jclepro.2016.04.150

Gao, W., Zhang, Y., Ramanujan, D., Ramani, K., Chen, Y., Williams, C. B., ... Zavattieri, P. D. (2015). The status, challenges, and future of additive manufacturing in engineering. Computer-Aided Design, 69, 65-89. http://doi.org/10.1016/j.cad.2015.04.001

Gaub, H. (2015). Customization of mass-produced parts by combining injection molding and additive manufacturing with Industry 4.0 technologies. Reinforced Plastics.

Gebler, M., Schoot Uiterkamp, A. J. M., \& Visser, C. (2014). A global sustainability perspective on 3D printing technologies. Energy Policy, 74, 158-167. http://doi.org/10.1016/j.enpol.2014.08.033

Giret, A., Trentesaux, D., \& Prabhu, V. (2015). Sustainability in manufacturing operations scheduling: A state of the art review. Journal of Manufacturing Systems, 37, Part 1, 126-140. http://doi.org/10.1016/j.jmsy.2015.08.002

Go, J., \& Hart, A. J. (2016). A framework for teaching the fundamentals of additive manufacturing and enabling rapid innovation. Additive Manufacturing, 10, 76-87. http://doi.org/10.1016/j.addma.2016.03.001

Gress, D. R., \& Kalafsky, R. V. (2015). Geographies of production in 3D: Theoretical and research implications stemming from additive manufacturing. Geoforum, 60, 43-52. http://doi.org/10.1016/j.geoforum.2015.01.003

Gupta, K., Laubscher, R. F., Davim, J. P., \& Jain, N. K. (2016). Recent developments in sustainable manufacturing of gears: a review. Journal of Cleaner Production, 112, Part 4, 3320-3330. http://doi.org/10.1016/j.jclepro.2015.09.133

Hague, R., Campbell, I., \& Dickens, P. (2003). Implications on design of rapid manufacturing. Proceedings of the Institution of Mechanical Engineers, Part C: Journal of Mechanical Engineering Science, 217(1), 25-30.

Hedrick, R. W., Urbanic, R. J., \& Burford, C. G. (2015). Development Considerations for an Additive Manufacturing CAM System. IFAC-PapersOnLine, 48(3), 2327-2332. http://doi.org/10.1016/j.ifacol.2015.06.435

Hinojos, A., Mireles, J., Reichardt, A., Frigola, P., Hosemann, P., Murr, L. E., \& Wicker, R. B. (2016). Joining of Inconel 718 and 316 Stainless Steel using electron beam melting additive manufacturing technology. Materials \& Design, 94, 17-27. http://doi.org/10.1016/j.matdes.2016.01.041

Hopkinson, N., \& Dicknes, P. (2003). Analysis of rapid manufacturing - using layer manufacturing processes for production. Proceedings of the Institution of Mechanical Engineers, Part C: Journal of Mechanical Engineering Science, 217(1), 31-39.

Huang, R., Riddle, M., Graziano, D., Warren, J., Das, S., Nimbalkar, S., ... Masanet, E. (n.d.). Energy and emissions saving potential of additive manufacturing: the case of lightweight aircraft components. Journal of Cleaner Production. http://doi.org/10.1016/j.jclepro.2015.04.109

Hull, C. W. (1986). Apparatus for production of three-dimensional objects by stereolithography. Google Patents. Retrieved from http://www.google.com/patents/us4575330

Huynh, L., Rotella, J., \& Sangid, M. D. (n.d.). Fatigue behavior of IN718 microtrusses produced via additive manufacturing. Materials \& Design. http://doi.org/10.1016/j.matdes.2016.05.032 
Jia, F., Wang, X., Mustafee, N., \& Hao, L. (2016). Investigating the feasibility of supply chain-centric business models in 3D chocolate printing: A simulation study. Technological Forecasting and Social Change, 102, 202-213. http://doi.org/10.1016/j.techfore.2015.07.026

Khajavi, S. H., Partanen, J., \& Holmström, J. (2014). Additive manufacturing in the spare parts supply chain. Computers in Industry, 65(1), 50-63. http://doi.org/10.1016/j.compind.2013.07.008

Kianian, B., Tavassoli, S., Larsson, T. C., \& Diegel, O. (2016). The Adoption of Additive Manufacturing Technology in Sweden. Procedia CIRP, 40, 7-12. http://doi.org/10.1016/j.procir.2016.01.036

Klahn, C., Leutenecker, B., \& Meboldt, M. (2015). Design Strategies for the Process of Additive Manufacturing. Procedia CIRP, 36, 230-235. http://doi.org/10.1016/j.procir.2015.01.082

L. Rickenbacher, A. Spierings, \& K. Wegener. (2013). An integrated cost-model for selective laser melting (SLM). Rapid Prototyping Journal, 19(3), 208-214. http://doi.org/10.1108/13552541311312201

Le Bourhis, F., Dipartimento per gli affari giuridici e legislativi, Dembinski, L., Hascoet, J.-Y., \& Mognol, P. (2014). Predictive Model for Environmental Assessment in Additive Manufacturing Process. Procedia CIRP, 15, 26-31. http://doi.org/10.1016/j.procir.2014.06.031

Lim, S., Buswell, R. A., Le, T. T., Austin, S. A., Gibb, A. G., \& Thorpe, T. (2012). Developments in construction-scale additive manufacturing processes. Automation in Construction, 21, 262-268.

Lindemann, C., Jahnke, U., Moi, M., \& Koch, R. (2012). Analyzing product lifecycle costs for a better understanding of cost drivers in additive manufacturing. In 23th Annual International Solid Freeform Fabrication Symposium-An Additive Manufacturing Conference. Austin Texas USA 6th-8th August.

Lindemann, C., Reiher, T., Jahnke, U., \& Koch, R. (2015). Towards a sustainable and economic selection of part candidates for additive manufacturing. Rapid Prototyping Journal, 21(2), 216-227.

List, F. A., Dehoff, R. R., Lowe, L. E., \& Sames, W. J. (2014). Properties of Inconel 625 mesh structures grown by electron beam additive manufacturing. Materials Science and Engineering: A, 615, 191197. http://doi.org/10.1016/j.msea.2014.07.051

Ma, Y., Cuiuri, D., Li, H., Pan, Z., \& Shen, C. (2016). The effect of postproduction heat treatment on $\gamma$ TiAl alloys produced by the GTAW-based additive manufacturing process. Materials Science and Engineering: A, 657, 86-95. http://doi.org/10.1016/j.msea.2016.01.060

Manogharan, G., Wysk, R. A., \& Harrysson, O. L. A. (2016). Additive manufacturing-integrated hybrid manufacturing and subtractive processes: Economic model and analysis. International Journal of $\begin{array}{llll}\text { Computer } & \text { Integrated } & \text { Manufacturing, } & \text { 47(5), }\end{array}$ http://doi.org/10.1080/0951192X.2015.1067920

Manogharan, G., Wysk, R., Harrysson, O., \& Aman, R. (2015). AIMS - A Metal Additive-hybrid Manufacturing System: System Architecture and Attributes. Procedia Manufacturing, 1, 273-286. http://doi.org/10.1016/j.promfg.2015.09.021

Mellor, S., Hao, L., \& Zhang, D. (2014). Additive manufacturing: A framework for implementation. International Journal of Production Economics, 149, 194-201.

Muita, K., Westerlund, M., \& Rajala, R. (2015). The Evolution of Rapid Production: How to Adopt Novel Manufacturing Technology. IFAC-PapersOnLine, 48(3), 32-37. http://doi.org/10.1016/j.ifacol.2015.06.054

Naghieh, S., Karamooz Ravari, M. R., Badrossamay, M., Foroozmehr, E., \& Kadkhodaei, M. (2016). Numerical investigation of the mechanical properties of the additive manufactured bone scaffolds fabricated by FDM: The effect of layer penetration and post-heating. Journal of the Mechanical Behavior of Biomedical Materials, 59, 241-250. http://doi.org/10.1016/j.jmbbm.2016.01.031

Newman, S. T., Zhu, Z., Dhokia, V., \& Shokrani, A. (2015). Process planning for additive and subtractive manufacturing technologies. CIRP Annals-Manufacturing Technology, 64(1), 467-470.

Nickels, L. (2016). Additive manufacturing: A user's guide. Metal Powder Report, 71(2), 100-105. http://doi.org/10.1016/j.mprp.2016.02.045

Nouri, H., Guessasma, S., \& Belhabib, S. (2016). Structural imperfections in additive manufacturing perceived from the X-ray micro-tomography perspective. Journal of Materials Processing Technology, 234, 113-124. http://doi.org/10.1016/j.jmatprotec.2016.03.019 
Nyamekye, P., Leino, M., Piili, H., \& Salminen, A. (2015). Overview of Sustainability Studies of CNC Machining and LAM of Stainless Steel. Physics Procedia, 78, 367-376. http://doi.org/10.1016/j.phpro.2015.11.051

Ordás, N., Ardila, L. C., Iturriza, I., Garcianda, F., Álvarez, P., \& García-Rosales, C. (2015). Fabrication of TBMs cooling structures demonstrators using additive manufacturing (AM) technology and HIP. Fusion Engineering and Design, 96-97, 142-148. http://doi.org/10.1016/j.fusengdes.2015.05.059

Palanivel, S., Dutt, A. K., Faierson, E. J., \& Mishra, R. S. (2016). Spatially dependent properties in a laser additive manufactured Ti-6Al-4V component. Materials Science and Engineering: A, 654, 3952. http://doi.org/10.1016/j.msea.2015.12.021

Park, S., \& Rosen, D. W. (n.d.). Quantifying effects of material extrusion additive manufacturing process on mechanical properties of lattice structures using as-fabricated voxel modeling. Additive Manufacturing. http://doi.org/10.1016/j.addma.2016.05.006

Park, S.-I., Rosen, D. W., Choi, S., \& Duty, C. E. (2014). Effective mechanical properties of lattice material fabricated by material extrusion additive manufacturing. Additive Manufacturing, 1-4, 12 23. http://doi.org/10.1016/j.addma.2014.07.002

Petek Gursel, A., Masanet, E., Horvath, A., \& Stadel, A. (2014). Life-cycle inventory analysis of concrete production: A critical review. Cement and Concrete Composites, 51, 38-48. http://doi.org/10.1016/j.cemconcomp.2014.03.005

Piili, H., Happonen, A., Väistö, T., Venkataramanan, V., Partanen, J., \& Salminen, A. (2015). Cost Estimation of Laser Additive Manufacturing of Stainless Steel. Physics Procedia, 78, 388-396. http://doi.org/10.1016/j.phpro.2015.11.053

Pinkerton, A. J. (2016). [INVITED] Lasers in additive manufacturing. Optics \& Laser Technology, 78, Part A, 25-32. http://doi.org/10.1016/j.optlastec.2015.09.025

Quan, Z., Larimore, Z., Wu, A., Yu, J., Qin, X., Mirotznik, M., ... Chou, T.-W. (2016). Microstructural design and additive manufacturing and characterization of 3D orthogonal short carbon fiber/acrylonitrile-butadiene-styrene preform and composite. Composites Science and Technology, 126, 139-148. http://doi.org/10.1016/j.compscitech.2016.02.021

Rayna, T., \& Striukova, L. (2016). From rapid prototyping to home fabrication: How 3D printing is changing business model innovation. Technological Forecasting and Social Change, 102, 214-224. http://doi.org/10.1016/j.techfore.2015.07.023

Ruffo, M., \& Hague, R. (2007). Cost estimation for rapid manufacturing'simultaneous production of mixed components using laser sintering. Proceedings of the Institution of Mechanical Engineers, Part B: Journal of Engineering Manufacture, 221(11), 1585-1591.

Ruffo, M., Tuck, C., \& Hague, R. (2006). Cost estimation for rapid manufacturing-laser sintering production for low to medium volumes. Proceedings of the Institution of Mechanical Engineers, Part B: Journal of Engineering Manufacture, 220(9), 1417-1427.

Sahebrao Ingole, D., Madhusudan Kuthe, A., Thakare, S. B., \& Talankar, A. S. (2009). Rapid prototyping-a technology transfer approach for development of rapid tooling. Rapid Prototyping Journal, 15(4), 280-290.

Scholz, S., Mueller, T., Plasch, M., Limbeck, H., Adamietz, R., Iseringhausen, T., ... Woegerer, C. (2016). A modular flexible scalable and reconfigurable system for manufacturing of Microsystems based on additive manufacturing and e-printing. Robotics and Computer-Integrated Manufacturing, 40, 14-23. http://doi.org/10.1016/j.rcim.2015.12.006

Schröder, M., Falk, B., \& Schmitt, R. (2015). Evaluation of Cost Structures of Additive Manufacturing Processes Using a New Business Model. Procedia CIRP, 30, 311-316.

Scott, A., \& Harrison, T. P. (2015). Additive Manufacturing in an End-to-End Supply Chain Setting. 3D Printing and Additive Manufacturing, 2(2), 65-77.

Shamsaei, N., Yadollahi, A., Bian, L., \& Thompson, S. M. (2015). An overview of Direct Laser Deposition for additive manufacturing; Part II: Mechanical behavior, process parameter optimization and control. Additive Manufacturing, 8, 12-35. http://doi.org/10.1016/j.addma.2015.07.002

Silva, J. V. L., \& Rezende, R. A. (2013). Additive Manufacturing and its future impact in logistics. IFAC Proceedings Volumes, 46(24), 277-282. http://doi.org/10.3182/20130911-3-BR-3021.00126 
Sreenivasan, R., Goel, A., \& Bourell, D. L. (2010). Sustainability issues in laser-based additive manufacturing. Physics Procedia, 5, 81-90.

Stock, T., \& Seliger, G. (2016). Opportunities of Sustainable Manufacturing in Industry 4.0. Procedia CIRP, 40, 536-541. http://doi.org/10.1016/j.procir.2016.01.129

Stucker, B. (2012). Additive manufacturing technologies: technology introduction and business implications. In Frontiers of Engineering: Reports on Leading-Edge Engineering From the 2011 Symposium, National Academies Press, Washington, DC, Sept (pp. 19-21).

Thomas, D. (2015). Costs, benefits, and adoption of additive manufacturing: a supply chain perspective. The International Journal of Advanced Manufacturing Technology, 1-20.

Thompson, S. M., Bian, L., Shamsaei, N., \& Yadollahi, A. (2015). An overview of Direct Laser Deposition for additive manufacturing; Part I: Transport phenomena, modeling and diagnostics. Additive Manufacturing, 8, 36-62. http://doi.org/10.1016/j.addma.2015.07.001

Uhlmann, E., Kersting, R., Klein, T. B., Cruz, M. F., \& Borille, A. V. (2015). Additive Manufacturing of Titanium Alloy for Aircraft Components. Procedia CIRP, 35, 55-60. http://doi.org/10.1016/j.procir.2015.08.061

Wang, X., Gong, X., \& Chou, K. (2015). Scanning Speed Effect on Mechanical Properties of Ti-6Al-4V Alloy Processed by Electron Beam Additive Manufacturing. Procedia Manufacturing, 1, 287-295. http://doi.org/10.1016/j.promfg.2015.09.026

Wang, Z., Palmer, T. A., \& Beese, A. M. (2016). Effect of processing parameters on microstructure and tensile properties of austenitic stainless steel 304L made by directed energy deposition additive manufacturing. Acta Materialia, 110, 226-235. http://doi.org/10.1016/j.actamat.2016.03.019

Watson, J. K., \& Taminger, K. M. B. (n.d.). A decision-support model for selecting additive manufacturing versus subtractive manufacturing based on energy consumption. Journal of Cleaner Production. http://doi.org/10.1016/j.jclepro.2015.12.009

Weller, C., Kleer, R., \& Piller, F. T. (2015). Economic implications of 3D printing: Market structure models in light of additive manufacturing revisited. International Journal of Production Economics, $164,43-56$.

Winkless, L. (2015). Is additive manufacturing truly the future? Metal Powder Report, 70(5), 229-232. http://doi.org/10.1016/j.mprp.2015.05.003

Witherell, P., Herron, J., \& Ameta, G. (2016). Towards Annotations and Product Definitions for Additive Manufacturing. Procedia CIRP, 43, 339-344. http://doi.org/10.1016/j.procir.2016.01.198

Wits, W. W., García, J. R. R., \& Becker, J. M. J. (2016). How Additive Manufacturing Enables more Sustainable End-user Maintenance, Repair and Overhaul (MRO) Strategies. Procedia CIRP, 40, 693698. http://doi.org/10.1016/j.procir.2016.01.156

Wong, K. V., \& Hernandez, A. (2012). A review of additive manufacturing. ISRN Mechanical Engineering, 2012. Retrieved from http://downloads.hindawi.com/journals/isrn.mechanical.engineering/2012/208760.pdf

Würtz, G., Lasi, H., \& Morar, D. (2015). Additive Manufacturing - Enabling Technology for Lifecycle Oriented Value-increase or Value-decrease. Procedia CIRP, 33, 394-399. http://doi.org/10.1016/j.procir.2015.06.092

Yang, L., Harrysson, O., West, H., \& Cormier, D. (2015). Mechanical properties of 3D re-entrant honeycomb auxetic structures realized via additive manufacturing. International Journal of Solids and Structures, 69-70, 475-490. http://doi.org/10.1016/j.ijsolstr.2015.05.005

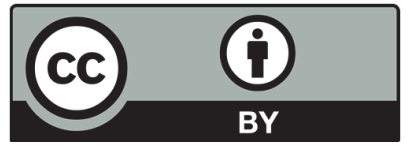

C 2016 by the authors; licensee Growing Science, Canada. This is an open access article distributed under the terms and conditions of the Creative Commons Attribution (CCBY) license (http://creativecommons.org/licenses/by/4.0/). 